\title{
Multifunctional nanocomposites of poly(vinylidene fluoride) reinforced by carbon nanotubes and magnetite nanoparticles
}

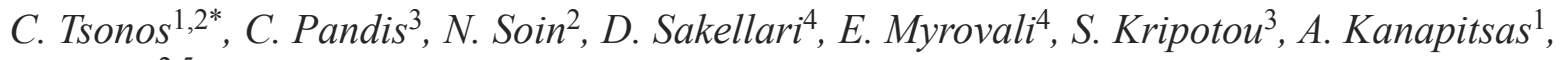 \\ E. Siores ${ }^{2,5}$
}

${ }^{1}$ Electronics Engineering Department, Technological Educational Institute (TEI) of Sterea Ellada, 35100 Lamia, Greece ${ }^{2}$ Institute for Materials Research and Innovation (IMRI), University of Bolton, Deane Road, BL3 5AB Bolton, UK ${ }^{3}$ Physics Department, National Technical University of Athens, Zografou 15780 Athens, Greece

${ }^{4}$ Department of Physics, Aristotle University of Thessaloniki, 54124 Thessaloniki, Greece

${ }^{5}$ Technological Educational Institute of Athens, 12210 Athens, Greece

Received 12 May 2015; accepted in revised form 27 July 2015

\begin{abstract}
In the present study, the effect of nano magnetite $\left(\mathrm{Fe}_{3} \mathrm{O}_{4}\right)$ content on structural, dielectric/electrical, magnetic and thermal properties of poly(vinylidene fluoride)/carbon nanotubes matrix, is investigated. Nanocomposite films of polyvinylidene fluoride, carbon nanotubes and $\mathrm{Fe}_{3} \mathrm{O}_{4}$ nanoparticles were prepared by the twin screw compounding method. $\mathrm{Fe}_{3} \mathrm{O}_{4}$, as magnetic inclusions was incorporated into the composites with carbon nanotubes loadings well above the percolation threshold, where conductive networks were formed. Magnetic characterization revealed the ferrimagnetic behavior of nanocomposites, with saturation magnetization values depending on magnetite content. Results obtained from the analysis of Fourier Transform Infrared Spectroscopy (FTIR), X-ray Diffraction (XRD) and Differential Scanning Calorimetry (DSC) techniques were very informative for the study of the polymorphism and crystallinity in PVDF. The incorporation of $\mathrm{Fe}_{3} \mathrm{O}_{4}$ inclusions in PVDF/CNT matrix, gradually increase both electrical conductivity and dielectric permittivity up to $10 \mathrm{wt} \% \mathrm{Fe}_{3} \mathrm{O}_{4}$ content, while at the higher $\mathrm{Fe}_{3} \mathrm{O}_{4}$ content $(15 \mathrm{wt} \%)$ reduced values were obtained. This behavior, at higher $\mathrm{Fe}_{3} \mathrm{O}_{4}$ content, should be possible related to the insulating and barrier role of $\mathrm{Fe}_{3} \mathrm{O}_{4}$ nanoparticles.
\end{abstract}

Keywords: nanocomposites, dielectric properties, thermal properties

\section{Introduction}

A great challenge in materials engineering is the production of multifunctional nanocomposites, which combine inexpensive materials with the ease of processing at large scale. Polyvinylidene fluoride (PVDF), is a semi-crystalline polymer having remarkable thermal stability, good chemical resistance and extraordinary pyroelectric and piezoelectric properties among polymers [1]. These properties combined with its high elasticity, relative transparency and ease of processing, make this material suitable for various technological applications [2]. PVDF shows a complex structure and it can exhibit five distinct crystalline phases related to different chain conformations, known as $\alpha, \beta, \gamma, \delta$ and $\varepsilon$ phases $[3,4]$. Amongst them, $\beta$ phase is the most active phase electrically and, to a lesser extent, $\gamma$ phase. Thus, the use of PVDF as matrix in nanocomposites is one of the key parameters for a wide range of applications. Adding nanoparticles to a matrix such as PVDF can enhance its conductive performance and provide enhanced responses by capitalizing on the nature and properties of the nanoscale filler. The final properties of these nanocomposites mainly depend on

\footnotetext{
*Corresponding author, e-mail: tsonos@teilam.gr

(C) BME-PT
} 
parameters such as filler size, method of preparation and the dispersion of nanoparticles into the polymer matrix [5-7].

Among the nanosized fillers, iron oxides have become of long standing interest, because of their diverse variety of applications in electronic, magnetic, optical, and mechanical devices [8]. Iron oxide magnetic nanoparticles are one of most studied nanomaterials, especially due to their magnetic properties, biocompatibility, biodegradability and low cost. Magnetoelectric materials are a relatively new class of materials, where their magnetic nanoparticles and polymer matrix allow a variety of applications in electronic, magnetic, optical, and mechanical devices $[9,10]$. Magnetoelectric composites have become one of the most active research fields in the areas of materials science and engineering in recent years. $\mathrm{Fe}_{3} \mathrm{O}_{4}$ nanoparticles and their composites have attracted enhanced attention and their critical size for superparamagnetic to ferrimagnetic transition has been determined to be near $30 \mathrm{~nm}$ at room temperature [11]. $\mathrm{PVDF} / \mathrm{Fe}_{3} \mathrm{O}_{4}$ composites exhibit superparamagnetic behavior with the presence of $\mathrm{Fe}_{3} \mathrm{O}_{4}$ nanoparticles, while the maximum for saturation magnetization was found to be $30.8 \mathrm{emu} / \mathrm{g}$ [12]. In composite films of $\mathrm{PVDF} / \mathrm{Fe}_{3} \mathrm{O}_{4}$ which are fabricated by solvent casting method, it was found that the inclusion of nanosized $\mathrm{Fe}_{3} \mathrm{O}_{4}$ significantly enhances the crystallinity of PVDF and the $\beta$ phase content [13]. Also, increased crystallinity enhances the ferrimagnetic properties of these composites whereas the latter improves the thermal stability and polarization effects. In another similar system, differential scanning calorimetry measurements revealed that the crystallinity of PVDF decreased with the addition of $\mathrm{Fe}_{3} \mathrm{O}_{4}$, while the conductivity of the composite films increased with increase in $\mathrm{Fe}_{3} \mathrm{O}_{4}$ content [14]. $\mathrm{Fe}_{3} \mathrm{O}_{4}$ nanoparticles were found to form some $50 \mathrm{~nm}-5 \mu \mathrm{m}$ conglomerates in the PVDF matrices while the size of these conglomerates increased with the increase in $\mathrm{Fe}_{3} \mathrm{O}_{4}$ content [15].

Also, much work has been done in order to investigate the effect of carbon nanotubes (CNT) addition on the crystallization, the mechanical, electrical and thermal properties of PVDF/CNT composites. Furthermore the addition of a third phase in the form of inorganic inclusions has been explored with the aim to enhance the multifunctionality of the prepared ternary composites. For example, in very recent works on ternary PVDF/CNT composites it has been shown that the addition of graphene oxide enhances the thermal conductivity [16], while $\mathrm{BaTiO}_{3}$ incorporation greatly increases the dielectric permittivity [17]. The present work deals with a novel three-phase PVDF based system with CNT and nanosized $\mathrm{Fe}_{3} \mathrm{O}_{4}$ as inclusions. To the best of our knowledge, there is no systematic work on PVDF/CNT/ $/ \mathrm{Fe}_{3} \mathrm{O}_{4}$ ternary composites in the literature. This system comprises a new type of multifunctional materials that combine the ferroelectric and piezoelectric properties of PVDF with the electrical properties of CNT and the magnetic properties of $\mathrm{Fe}_{3} \mathrm{O}_{4} \cdot \mathrm{Fe}_{3} \mathrm{O}_{4}$ nanoparticles were incorporated into the composites in various contents with CNT loadings well above the percolation threshold, where stable conductive networks were formed $[18,19]$. The effect of $\mathrm{Fe}_{3} \mathrm{O}_{4}$ nanoparticles on PVDF/CNT blends, and especially the insulating and barrier role of these inclusions on both, dielectric response and conductive network formation of $\mathrm{PVDF} / \mathrm{CNT}$ matrix, was investigated in this study.

\section{Experimental details \\ 2.1. Materials}

Samples were composed of PVDF with suitable additives $\left(\mathrm{CNT}, \mathrm{Fe}_{3} \mathrm{O}_{4}\right)$ in the desired loading range of 4 to $19 \mathrm{wt} \%$ (total). More specifically, CNT content was kept constant and equal to $4 \mathrm{wt} \%$ while $\mathrm{Fe}_{3} \mathrm{O}_{4}$ contents were $0,5,10$ and $15 \mathrm{wt} \%$. PVDF was compounded with the nanofillers using a lab scale twin screw compounder (Thermo Scientific) with counter rotating screws. A PVDF homopolymer, SOLEF 1008 (from Solvay Solexis) was used for the production of samples. The polymer had melt flow index (MFI) of $8 \mathrm{~g} / 10 \mathrm{~min}$ at $230^{\circ} \mathrm{C}$ (under a load of $2.16 \mathrm{~kg}$ ). Multiwalled CNT were obtained from Cheap Tubes Inc. with a mean outer diameter of $<10 \mathrm{~nm}$, length of $10-30 \mu \mathrm{m}$, purity $>90 \%$ (by wt $\%$ ) and an ash content of less than $1.5 \mathrm{wt} \%$. No further purification or acid treatment of the CNT was carried out and the samples were used as-received. $\mathrm{Fe}_{3} \mathrm{O}_{4}$ nanopowder was obtained from Aldrich with average particle size $<50 \mathrm{~nm}$ and purity $>98 \%$. The PVDF pellets (500 grams) were mixed with the suitable weight of additive and then passed through the twin screw extruder. Extruder temperature profile was set at $150^{\circ} \mathrm{C}$ (at hopper end) with $10^{\circ} \mathrm{C}$ incremental changes across the heated barrel $(165,175$, $185,195^{\circ} \mathrm{C}$ ) with a final temperature of $195^{\circ} \mathrm{C}$ at the die head. Temperature profile was set in such a manner that the polymer started to melt in the mid- 
dle of the barrel and then by the time it reached to the die head, the viscosity of it was reduced significantly. Polymer pellet-additive mixture was fed to the counter rotating screw at $13 \%$ feed rate and was moved across the length of the screw at $40 \%$ torque corresponding to $350 \mathrm{rpm}$ screw speed. Monofilament obtained from the die head was then passed through a cooling bath using a set of rollers from where it was passed onto a chopping unit which made homogeneous pellets ( $\sim 5 \mathrm{~mm}$ long) from it. The pellets were then dried overnight at $75^{\circ} \mathrm{C}$ to remove the adsorbed water before further processing. The samples were pressed at a pressure of $40 \mathrm{~kg} / \mathrm{cm}^{2}$ for duration of $2 \mathrm{~min} 30 \mathrm{sec}$ and then allowed to cool down at the same pressure using a cold press which rapidly cooled down the samples to room temperature in approximately 2 mins. The final sample weight was approximately $48 \mathrm{~g}$, with the rest of additive mix lost to overflow of the polymer to the outside of the mould. The twin screw compounding enabled better quality of mixing at low melt temperatures and hence the material degradation was avoided.

\subsection{Characterization}

Morphology was studied by field emission Scanning Electron Microscopy (FE-SEM) using FEI Nova nanoSEM 230 operating in high vacuum mode. Samples were cryofractured using liquid nitrogen and their cross section was examined using an accelerating voltage of $5 \mathrm{kV}$. The size of the particles from the SEM micrographs was measured using ImageJ software.

FTIR analysis was carried out using Thermo Scientific IS10 Nicolet FTIR spectrometer coupled with smart iTR accessory. A total of 64 scans at a resolution of $\pm 2 \mathrm{~cm}^{-1}$ were taken during spectrum acquisition. Vendor provided OMINIC software was used to analyze the results and calculations of the beta phase.

XRD analysis of samples was performed at room temperature using X'Pert MRD (Panalytical) between the $2 \theta$ range of $5-40^{\circ}$ at a scan speed of $0.02^{\circ} / \mathrm{s}$. A CuK $\alpha$ radiation $(\lambda=0.154 \mathrm{~nm})$ source performing at $45 \mathrm{kV}$ and $40 \mathrm{~mA}$ was used.

Thermal transitions (crystallization/melting) were studied by DSC analysis carried out in nitrogen atmosphere in the temperature range from 20 to $200^{\circ} \mathrm{C}$ using a Q20 (TA instrument) apparatus. The weight of the measured samples was kept constant at $\sim 5 \mathrm{mg}$. Heating and cooling rates were fixed to $10^{\circ} \mathrm{C} / \mathrm{min}$.

Magnetic measurements were performed, using Vibrating Sample Magnetometer (VSM) - Oxford $1.2 \mathrm{H} / \mathrm{CF} / \mathrm{HT}$ at maximum applied fields of $1 \mathrm{~T}$. For each sample magnetization versus applied field was recorded at room temperature.

Electrical/dielectric properties were studied by means of Dielectric Relaxation Spectroscopy (DRS) technique using Alpha analyzer in combination with a Quatro cryosystem for temperature control, both supplied by Novocontrol. Samples of $1 \mathrm{~mm}$ thickness were placed between two brass electrodes of $20 \mathrm{~mm}$ diameter and inserted as a capacitor in a Novocontrol sample cell. Golden electrodes were sputtered (using a sputter coater EMS 550) on both sides of the samples to assure good electrical contact between the sample and the gold-plated capacitor plates. The complex dielectric permittivity was recorded and measured in a broad frequency ranged from 1 to $10^{6} \mathrm{~Hz}$.

\section{Results and discussion}

\subsection{Morphology}

Figure 1 shows representative SEM micrographs of cryo-fractured surfaces obtained at magnification of $80000 \times$. Figure 1a shows the micrograph of pure PVDF for comparative analysis. The yellow squares for the samples containing CNT highlight the presence of several individual CNTs in the obtained micrographs (Figure 1b, a-c), indicative of a lack of agglomeration and presence of a good dispersion. It is important to note that the fractured samples were prepared using cryo-fracture and not the tensile fracture, which can sometimes lead to the fibrillation of PVDF and can be often misinterpreted as the CNT. Similarly, the green circles are indicative of the presence of $\mathrm{Fe}_{3} \mathrm{O}_{4}$ particles, which again show a good distribution across the PVDF matrix without significant agglomeration, having a mean diameter in the range of 50-100 nm. Furthermore, on increasing the $\mathrm{Fe}_{3} \mathrm{O}_{4}$ particle concentration to $15 \mathrm{wt} \%$ (sample $\left.\mathrm{PVDF} / \mathrm{CNT} /\left(\mathrm{Fe}_{3} \mathrm{O}_{4}\right)_{15 \%}\right)$ larger agglomerates of $\mathrm{Fe}_{3} \mathrm{O}_{4}$ were observed (Figure 1d).

\subsection{FTIR measurements}

To calculate relative amount of the $\beta$ phase in the composite film, FTIR tests for the pure PVDF and nanocomposites were undertaken and results are shown in Figure 2a. The polar $\beta$ phase is technolog- 


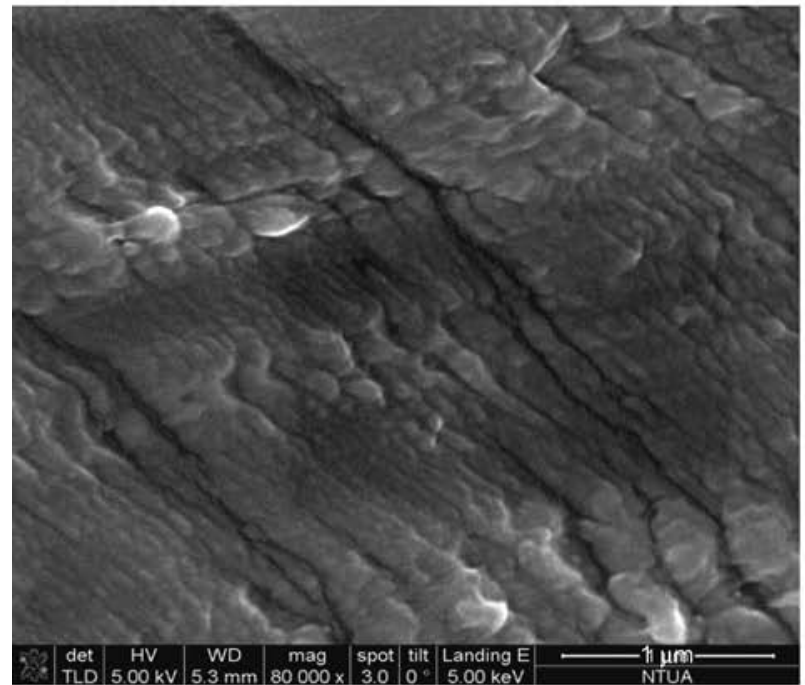

a)

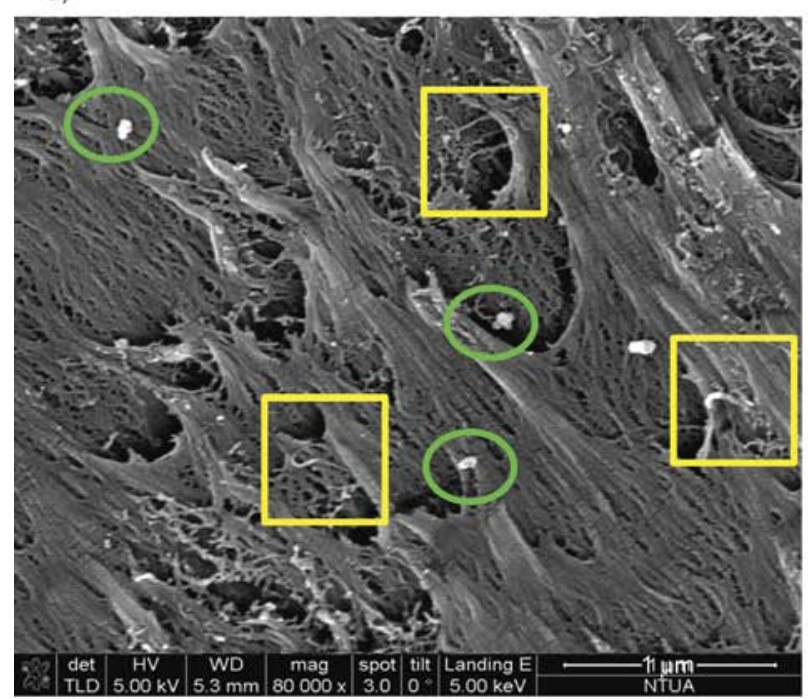

c)

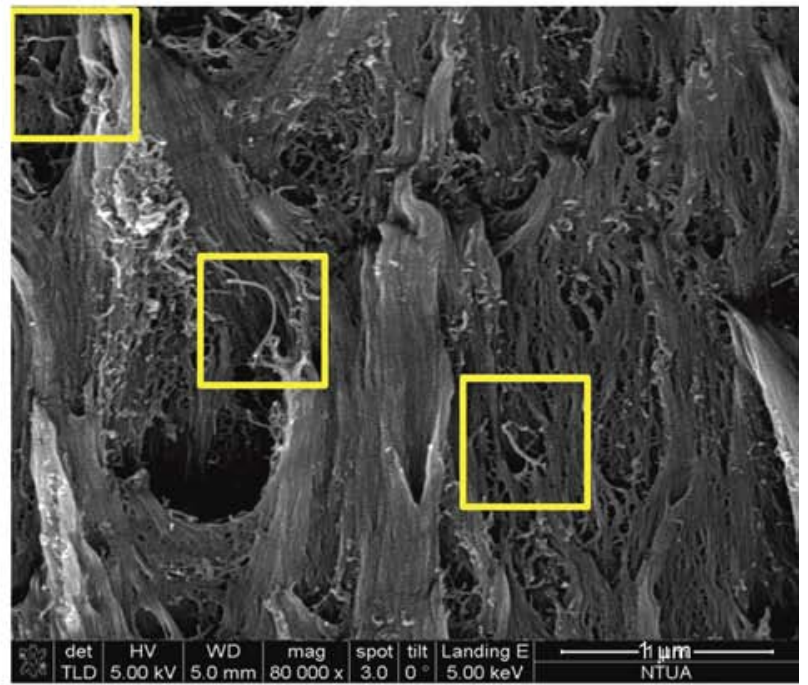

b)

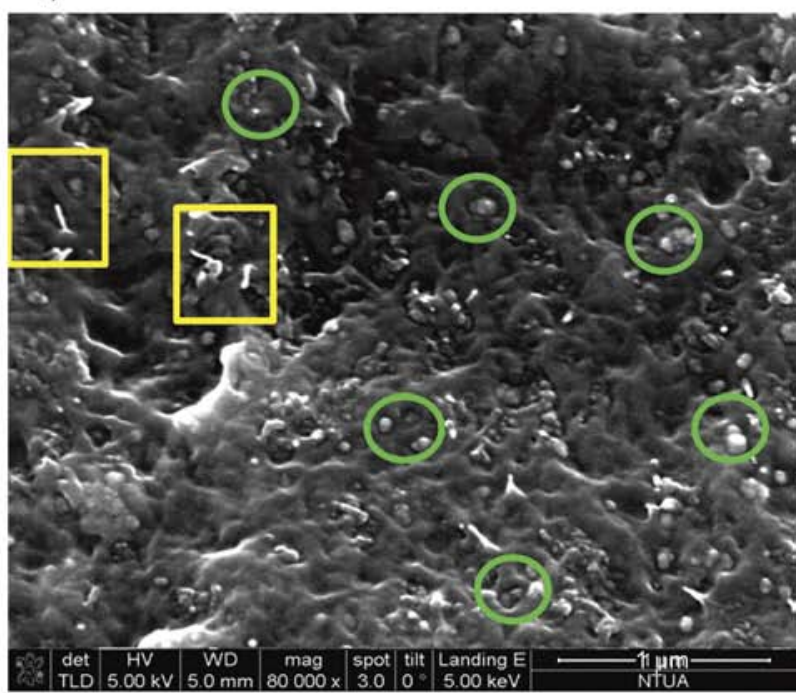

d)

Figure 1. FE-SEM micrographs obtained at $80000 \times$ magnification: (a) pure PVDF, (b) PVDF/CNT, (c) PVDF/CNT/ $\left(\mathrm{Fe}_{3} \mathrm{O}_{4}\right)_{5 \%}$, (d) $\mathrm{PVDF} / \mathrm{CNT} /\left(\mathrm{Fe}_{3} \mathrm{O}_{4}\right)_{15 \%}$

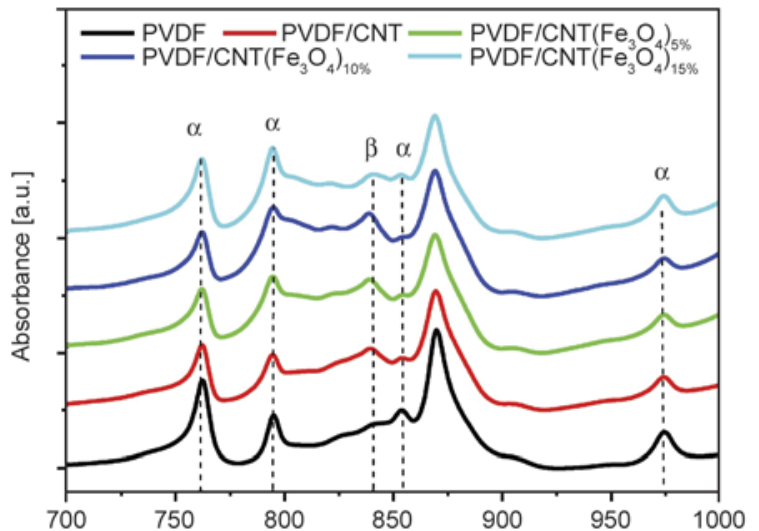

a)

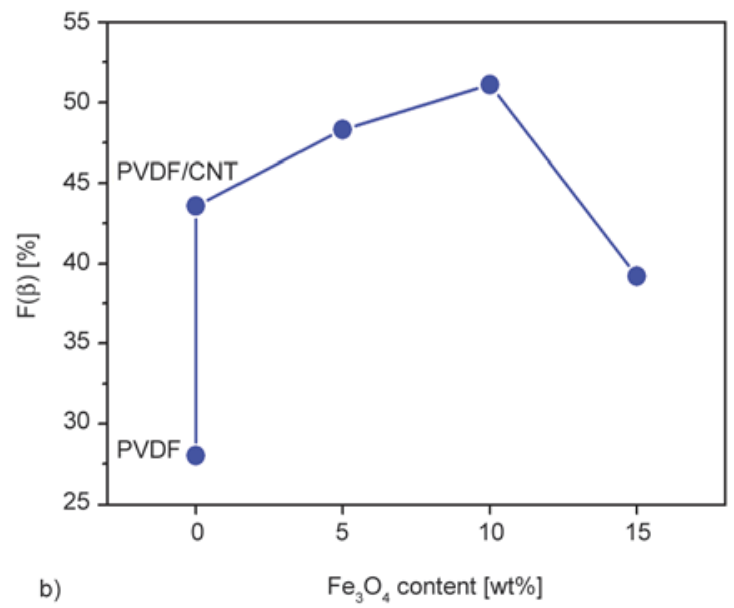

b)

$\mathrm{Fe}_{3} \mathrm{O}_{4}$ content $[\mathrm{wt} \%]$

Figure 2. (a) FTIR spectra for the PVDF nanocomposites, (b) $\beta$ phase content for the PVDF nanocomposites

ically most interesting as it shows the largest piezoelectric, ferroelectric and pyroelectric coefficients, as well as a high dielectric constant. Various charac- teristic absorption bands which correspond to the crystalline phases of PVDF systems have been reported [20-22], and some of these are present in 
Figure 1a. Absorbance at 612, 760, 795, 853 and $974 \mathrm{~cm}^{-1}$, correspond to the $\beta$ phase, while absorbances at $511,840,878$ and $1279 \mathrm{~cm}^{-1}$ corresponded to the $\beta$ phase. The content fraction of phase in each sample of PVDF nanocomposites, $F(\beta)$, was calculated according to Equation (1) [2325]:

$F(\beta)=\frac{X_{\beta}}{X_{\alpha}+X_{\beta}}=\frac{A_{\beta}}{1.26 A_{\alpha}+A_{\beta}}$

where $X_{\alpha}$ and $X_{\beta}$ are crystalline mass fractions of the $\alpha$ and $\beta$ phases and $A_{\alpha}, A_{\beta}$ correspond to their absorbance at 760 and $840 \mathrm{~cm}^{-1}$ respectively. This relation gives the relative amount of the $\alpha$ and $\beta$ phases in composites assuming that only these phases are present and has been used extensively in the literature. As shown in Figure $2 b$, the $\beta$ content calculated for pristine PVDF samples and PVDF/CNT composite shows a huge increase from approximately 28 to $44 \%$, signifying the effect of CNT in promoting the $\beta$ phase crystallization. Similar behaviour has been seen in PVDF based composites prepared by melt compounding, in which the incorporation of CNT produced transformation of the phase into $\beta$ phase $[26,27]$. Furthermore, the incor-

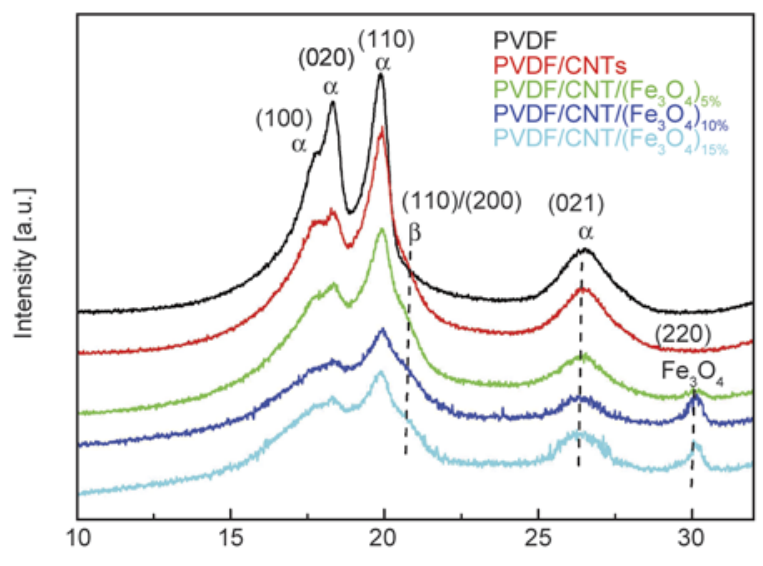

a)

$2 \theta\left[{ }^{\circ}\right]$ poration of $\mathrm{Fe}_{3} \mathrm{O}_{4}$ nanoparticles in PVDF/CNT matrix slightly and gradually increases the $\beta$ phase up to a maximum value of $51 \%$ for the sample with $10 \mathrm{wt} \% \mathrm{Fe}_{3} \mathrm{O}_{4}$, while at the highest $\mathrm{Fe}_{3} \mathrm{O}_{4}$ content (i.e. $15 \mathrm{wt} \%$ ) phase decreases to the value of $39 \%$. Adding $\mathrm{Fe}_{3} \mathrm{O}_{4}$ nanoparticles was found to result also in $\alpha$ to $\beta$ phase transformation in PVDF matrix $[28,29]$. From these results it seems that it is mainly CNT that promote the formation of phase in PVDF nanocomposites, while the influence of $\mathrm{Fe}_{3} \mathrm{O}_{4}$ is less but not insignificant.

\subsection{XRD analysis}

Figure 3a shows $\mathrm{X}$-ray diffractograms of pristine $\mathrm{PVDF}$ and PVDF/CNT nanocomposites with 5, 10, and $15 \mathrm{wt} \% \mathrm{Fe}_{3} \mathrm{O}_{4}$ in the $2 \theta$ range between $5-40^{\circ}$. The well-known diffraction peaks of $\alpha$ phase of PVDF appearing at $2 \theta=17.8,18.5,20$ and $26.8^{\circ}$, are assigned to the lattice planes of (100), (020), (110) and (021) respectively [30]. Furthermore, for samples containing $\mathrm{Fe}_{3} \mathrm{O}_{4}$ the diffraction peak at $30.6^{\circ}$ are assigned to $\mathrm{Fe}_{3} \mathrm{O}_{4}$ crystalline plane of (220) [13]. In fact, with the increase in the addition of $\mathrm{Fe}_{3} \mathrm{O}_{4}$, the peak becomes increasingly prominent. Interestingly, when CNT are incorporated in the PVDF

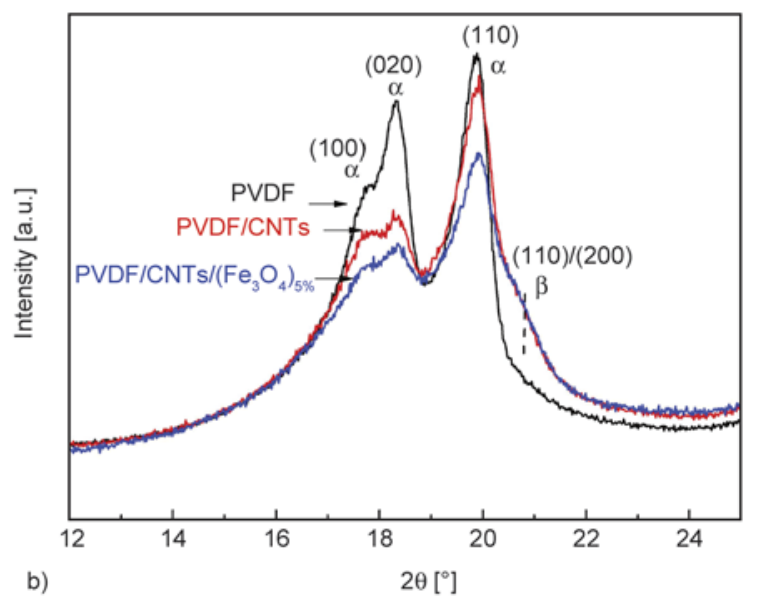

Figure 3. (a) XRD patterns of pure PVDF and PVDF nanocomposites with $\mathrm{CNT}$ and $\mathrm{Fe}_{3} \mathrm{O}_{4}$, (b) zoom of XRD patterns of pure PVDF and nanocomposites showing the existence of $\beta$ phase for the nanocomposites containing $\mathrm{CNT}$

Table 1. Results from DSC and XRD analysis

\begin{tabular}{|c|c|c|c|c|c|c|c|}
\hline \multirow{3}{*}{ Sample } & \multicolumn{6}{|c|}{ DSC } & \multirow{3}{*}{$\begin{array}{c}\text { XRD } \\
\mathbf{X}_{\mathbf{c}} \\
{[\%]}\end{array}$} \\
\hline & \multicolumn{2}{|c|}{ First heating } & \multicolumn{3}{|c|}{ Second heating } & First cooling & \\
\hline & $\begin{array}{c}\mathbf{T}_{\mathbf{m}} \\
{\left[{ }^{\circ} \mathbf{C}\right]}\end{array}$ & $\begin{array}{c}\mathbf{T}_{\mathbf{m} 2} \\
{\left[{ }^{\circ} \mathbf{C}\right]}\end{array}$ & $\begin{array}{c}\mathbf{T}_{\mathbf{m}} \\
{\left[{ }^{\circ} \mathbf{C}\right]}\end{array}$ & $\begin{array}{c}\Delta \mathbf{H} \\
{[\mathbf{J} / \mathbf{g}]}\end{array}$ & $\begin{array}{c}\mathbf{X}_{\mathbf{c}} \\
{[\%]}\end{array}$ & $\begin{array}{c}\mathbf{T}_{\mathbf{c}} \\
{\left[{ }^{\circ} \mathbf{C}\right]}\end{array}$ & \\
\hline PVDF & 173.0 & 165.5 & 171.4 & 50.6 & 48 & 137.70 & $49 \pm 2$ \\
\hline PVDF/CNT & 173.2 & 168.6 & 173.3 & 50.8 & 49 & 148.50 & $51 \pm 2$ \\
\hline $\mathrm{PVDF} / \mathrm{CNT} /\left(\mathrm{Fe}_{3} \mathrm{O}_{4}\right)_{5 \%}$ & 172.9 & 168.5 & 173.2 & 50.4 & 48 & 148.50 & $44 \pm 2$ \\
\hline $\mathrm{PVDF} / \mathrm{CNT} /\left(\mathrm{Fe}_{3} \mathrm{O}_{4}\right)_{10 \%}$ & 173.0 & 168.2 & 173.2 & 40.9 & 39 & 148.40 & $37 \pm 3$ \\
\hline $\mathrm{PVDF} / \mathrm{CNT} /\left(\mathrm{Fe}_{3} \mathrm{O}_{4}\right)_{15 \%}$ & 172.9 & 168.5 & 172.9 & 44.2 & 42 & 150.14 & $43 \pm 3$ \\
\hline
\end{tabular}


matrix, the appearance of a shoulder at $20.6^{\circ}$, attributed to the $(110) /(200)$ planes of the $\beta$ phase is observed [31]. The above can be seen more clearly in Figure $3 \mathrm{~b}$ where a zoom in the $2 \theta$ range between $12-25^{\circ}$ is presented. These findings suggest that the presence of CNT induces the formation of $\beta$ phase [32], in accordance with FTIR analysis. For the determination of the crystallinity from the XRD profiles, the following equation has been used [33], $X_{\mathrm{c}}=$ $I_{\mathrm{c}} /\left(I_{\mathrm{c}}+I_{\alpha}\right)$, where $I_{\mathrm{c}}$ and $I_{\alpha}$ are the integrated intensities scattered by the crystalline and the amorphous phases, respectively. The degree of crystallinity of PVDF in the nanocomposites has been evaluated from diffractograms and reported in Table 1.

\subsection{Thermal properties}

During the first heating scan a double melting peak is observed in all studied samples (Figure 4a). For pristine PVDF a main peak around $173^{\circ} \mathrm{C}$ and a shoulder around $166^{\circ} \mathrm{C}$ were observed. The existence of double melting peak is generally attributed to the presence of crystallites of different thickness, variety of crystallites perfection, re-melting of crystallites formed during heating or existence of polymorphism [13]. When the samples were cooled from the melt, a single crystallization peak was found and the crystallization temperature, $T_{\mathrm{c}}$, of pure PVDF was observed at $138^{\circ} \mathrm{C}$. In the nanocomposites, a narrower crystallization peak and a shift of crystallization temperature $T_{\mathrm{c}}$ to higher temperatures $\left(\sim 10^{\circ} \mathrm{C}\right)$ compared to pure PVDF was detected. Interestingly, $T_{\mathrm{c}}$ was found to be independent of the $\mathrm{Fe}_{3} \mathrm{O}_{4}$ concentration and their effect is less pronounced as can be seen in Figure 4c. The increase of $T_{\mathrm{c}}$ upon addition of CNT is a clear indication of their essence as nucleating agents promoting heterogeneous crystallization, a feature commonly observed in polymer/CNT nanocomposites [34, 35], while narrowing of the crystallization peak implies a narrower crystallite size distribution [36].

During the second heating scan and after erasing the thermal history of each sample, a single melting peak, independent of the filler concentration, was observed around $173^{\circ} \mathrm{C}$, slightly higher in the nanocomposites compared to pure PVDF (Figure 4b). Melting $\left(T_{\mathrm{m}}\right)$ and crystallization $\left(T_{\mathrm{c}}\right)$ temperatures together with the melting enthalpies $\left(\Delta H_{\mathrm{m}}\right)$ recorded during second heating scan are reported in Table 1. The degree of crystallinity $X_{\mathrm{c}}$ of PVDF is calculated from Equation (2):
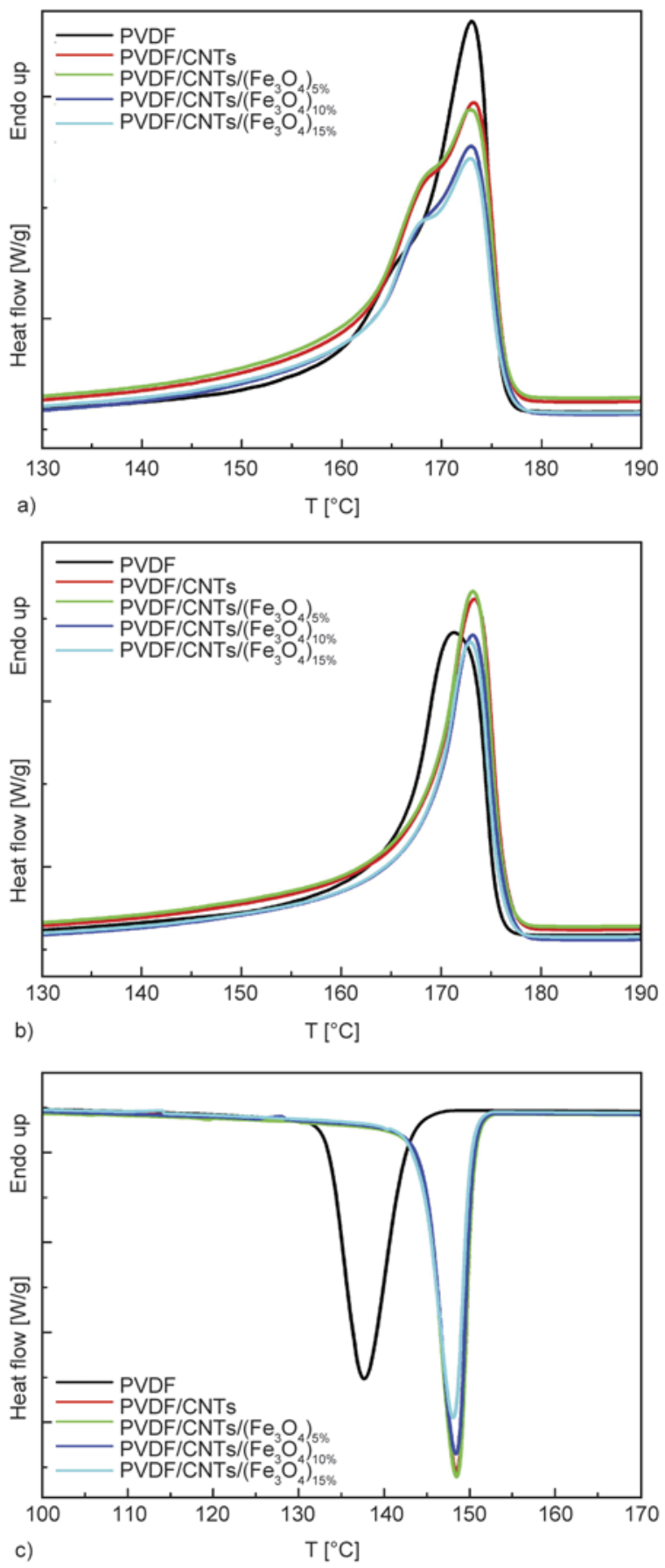

Figure 4. (a) DSC thermograms showing melting during first heating and (b) second heating scan, and (c) crystallization during cooling

$X_{\mathrm{c}}[\%]=\frac{\Delta H_{\mathrm{m}}}{(1-\varphi) \Delta H_{0}} \cdot 100$

where $\Delta H_{0}$ is the melting enthalpy for $100 \% \beta$ crystalline PVDF and $\varphi$ is the total weight fraction of fillers in nanocomposites. $\Delta H_{0}$ was taken equal to $104.5 \mathrm{~J} / \mathrm{g}$. [37]. The degree of crystallinity is practically unaffected by the addition of CNT and for the lowest concentration sample of $\mathrm{Fe}_{3} \mathrm{O}_{4}$ particles. For 
higher $\mathrm{Fe}_{3} \mathrm{O}_{4}$ content, a decrease of the degree of crystallinity was observed. A similar reduction in the crystallinity has been observed by other authors $[14$, 15]. This reduction in the crystallinity can be attributed to the inhibition effect of $\mathrm{Fe}_{3} \mathrm{O}_{4}$ addition on polymer crystal formation, similar to what has been observed with various other inorganic fillers. The above results are in accordance with those obtained from XRD analysis.

It should be noted that while DSC could be very accurate in the evaluation of the degree of crystallinity in PVDF, it could not be used in our case to distinguish between different polymorphs, in particular between $\alpha$ and $\beta$ phase. The melting temperatures of crystallite phases are very close and both appear in the range $167-172^{\circ} \mathrm{C}$ [24]. In addition, when analyzing DSC results in PVDF nanocomposites, further caution must be taken for ascribing the melting peaks to either $\alpha$ or $\beta$ phase, and DSC should be considered as complementary technique to FTIR or XRD, as its features are not only dependent on the crystalline phase, but also affected by crystalline defects which are particularly enhanced by the presence of nanofillers [30]. However, DSC is used to exclude the existence of $\gamma$ phase as no melting peak has been observed at higher temperatures around $179-180^{\circ} \mathrm{C}$ [38]. Combination of results analysis of all three techniques (FTIR, XRD and DSC) are very informative for the study of the polymorphism and crystallinity in PVDF. FTIR and XRD allowed identifying the different crystalline phases giving a clear evidence of the enhancement of $\beta$ phase of PVDF when CNT are incorporated, while DSC was used to evaluate the degree of crystallinity.

\subsection{Magnetic characterization}

Figure 5a presents hysteresis loops as recorded at room temperature for polymer nanocomposites, including $\mathrm{CNT}$ and $\mathrm{Fe}_{3} \mathrm{O}_{4}$ nanoparticles. The hysteresis loops confirm the ferromagnetic behavior of nanocomposites, which is attributed to magnetic nanoparticle content [13]. This magnetic behaviour is also observed in other similar composites systems [14]. Moreover, by increasing magnetite $\left(\mathrm{Fe}_{3} \mathrm{O}_{4}\right)$ content a gradual change in hysteresis loops is observed. Specifically, saturation magnetization $\left(M_{\mathrm{s}}\right)$ increases, from 2.9 to 7.0 and $10.8 \mathrm{emu} / \mathrm{g}$ for PVDF nanocomposites with 5,10 and $15 \mathrm{wt} \% \mathrm{Fe}_{3} \mathrm{O}_{4}$ content respectively. As compared to the saturation magnetization

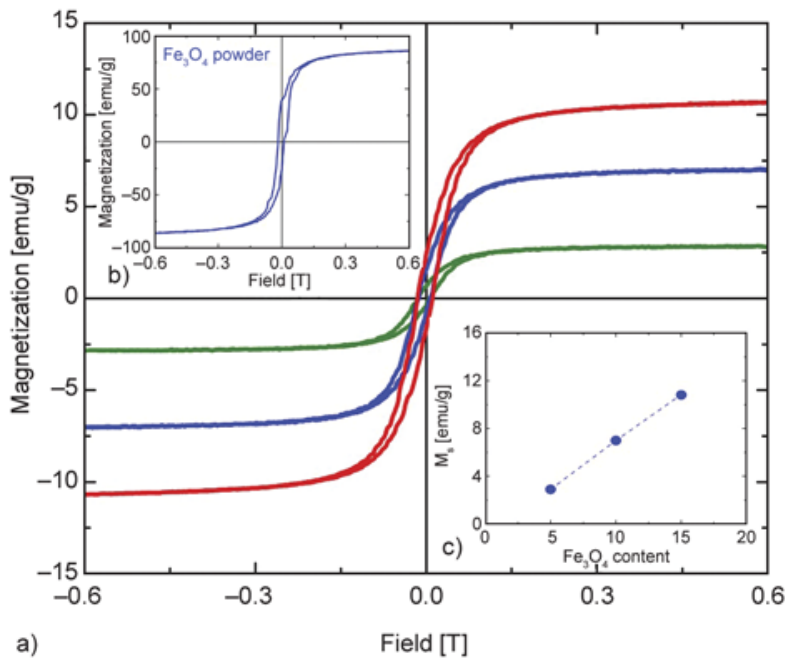

Figure 5. (a) Hysteresis loop recorded at room temperature for samples PVDF/CNT/( $\left.\mathrm{Fe}_{3} \mathrm{O}_{4}\right): 5,10$ and $15 \mathrm{wt} \%$ (green, blue and red respectively) in $\mathrm{Fe}_{3} \mathrm{O}_{4}$ content. Inset: saturation magnetization values with magnetite content, (b) Hysteresis loop recorded at room temperature for pure magnetite powder, (c) saturation magnetization values for magnetite nanocomposites as a function of $\mathrm{Fe}_{3} \mathrm{O}_{4}$ content.

value of $87.6 \mathrm{emu} / \mathrm{g}$ (Figure $5 \mathrm{~b}$ ), for the starting magnetite powder, these values are considerably lower due to their addition into a nonmagnetic polymer matrix as well as the low content (5-15 wt\%) of the $\mathrm{Fe}_{3} \mathrm{O}_{4}$ nanoparticles [39]. The observed linear increase in the values of saturation magnetization (Figure $5 \mathrm{c}$ inset) can, however, be attributed to the high dispersion of the magnetic nanoparticles in the polymer matrix and is in accordance with the results obtained by various other authors $[14,15,29]$.

\subsection{Electrical and dielectric characterization}

Figures $6 \mathrm{a}$ and $6 \mathrm{~b}$ show the variation of dielectric permittivity $\left(\varepsilon^{\prime}\right)$ and dielectric loss $\left(\varepsilon^{\prime \prime}\right)$ for PVDF and its nanocomposites, as a function of frequency at room temperature. In the low frequency region $\left(1-10^{3} \mathrm{~Hz}\right)$ for all the nanocomposites, there is a significant increase of $\varepsilon^{\prime}$ values, between two and three orders of magnitude as compared to pristine PVDF samples. In fact, for the PVDF/CNT composite itself, a huge increase is observed from $\sim 8$ (at $10 \mathrm{~Hz}$ ) to 2425 (at $10 \mathrm{~Hz}$ ), largely due to the interaction between the PVDF and CNT. It is interesting to note that the dielectric permitivitty of the composite is higher than the PVDF matrix (about 10) and of carbon nanotubes alone (about 2000), thereby hinting at the synergistic interactions between them. Accord- 
ing to the Maxwell-Wagner-Sillars (MWS) effect, when a current flows across the two-materials interfaces, charges can be accumulated at the interface between two dielectric materials with different relaxation times $(\tau=\varepsilon / \sigma$, where $\varepsilon$ is the dielectric permittivity and $\sigma$ is the conductivity). As the relaxation time of PVDF is significantly higher than that of CNT, the charge carriers are blocked at the internal interfaces due to the MWS effect, thereby enhancing the dielectric permittivity significantly. Moreover, in the study carried out by Yuan et al. [40], the formation of donor-acceptor complexes at the PVDF-CNT interfaces was shown to enhance the dielectric permittivity due to MWS effects. Now, as the $\mathrm{Fe}_{3} \mathrm{O}_{4}$ content increases in PVDF/CNT matrix, $\varepsilon^{\prime}$ values again gradually increase in the lower frequency region, while for the highest $\mathrm{Fe}_{3} \mathrm{O}_{4}$ content $(15 \mathrm{wt} \%), \varepsilon^{\prime}$ reduces below the corresponding values of PVDF/CNT. At $100 \mathrm{~Hz}$, the PVDF/CNT/ $\left(\mathrm{Fe}_{3} \mathrm{O}_{4}\right)_{15 \%}$ sample presents the lowest $\varepsilon^{\prime}$ value (1120) between all the PVDF/CNT/ $/ \mathrm{Fe}_{3} \mathrm{O}_{4}$ nanocomposites, while the maximum $\varepsilon^{\prime}$ value (12140) is exhibited by the PVDF/CNT/ $\left(\mathrm{Fe}_{3} \mathrm{O}_{4}\right)_{10 \%}$ sample. While the dielectric permittivity of $\mathrm{Fe}_{3} \mathrm{O}_{4}$ has a value below 100 at room temperature [41], it is obvious that the $\mathrm{Fe}_{3} \mathrm{O}_{4}$ nanoparticles play an important role on the dielectric properties of composites, with the increase in the $\varepsilon^{\prime}$ values (for 5 and $10 \mathrm{wt} \%$ $\mathrm{Fe}_{3} \mathrm{O}_{4}$ samples) caused by increasing the interfacial space-charge polarization between the polymer matrix and the $\mathrm{Fe}_{3} \mathrm{O}_{4}$ filler. Also, PVDF/CNT/ $\left(\mathrm{Fe}_{3} \mathrm{O}_{4}\right)_{10 \%}$ presents the highest stability in $\varepsilon^{\prime}$ values for frequencies below $100 \mathrm{kHz}$, an interesting property which could further be utilized for electronic devices.

Now, in the present system the content of CNT is higher than percolation threshold [18, 19], while the content of $\mathrm{Fe}_{3} \mathrm{O}_{4}$ is lower than the percolation threshold in $\mathrm{PVDF} / \mathrm{Fe}_{3} \mathrm{O}_{4}$ systems [12]. As mentioned above, by increasing the $\mathrm{Fe}_{3} \mathrm{O}_{4}$ content in PVDF/ $\mathrm{Fe}_{3} \mathrm{O}_{4}$ systems, $\varepsilon^{\prime}$ values gradually increase in low frequency region [12]. In the earlier work [12], it was observed that for $\mathrm{Fe}_{3} \mathrm{O}_{4}$ content of up to $6 \%$ volume fraction (similar concentration to our PVDF/ $\left.\mathrm{CNT} /\left(\mathrm{Fe}_{3} \mathrm{O}_{4}\right)_{15 \%}\right), \varepsilon^{\prime}$ reaches a value between $40-50$ at $100 \mathrm{~Hz}$. In our case, the dramatic increase of the dielectric permittivity to 7490 at $5 \mathrm{wt} \% \mathrm{Fe}_{3} \mathrm{O}_{4}$ content suggests that a synergistic effect occurs between the PVDF-CNT matrix and the $\mathrm{Fe}_{3} \mathrm{O}_{4}$ nanoparticles. As discussed earlier, the high dielectric permit-
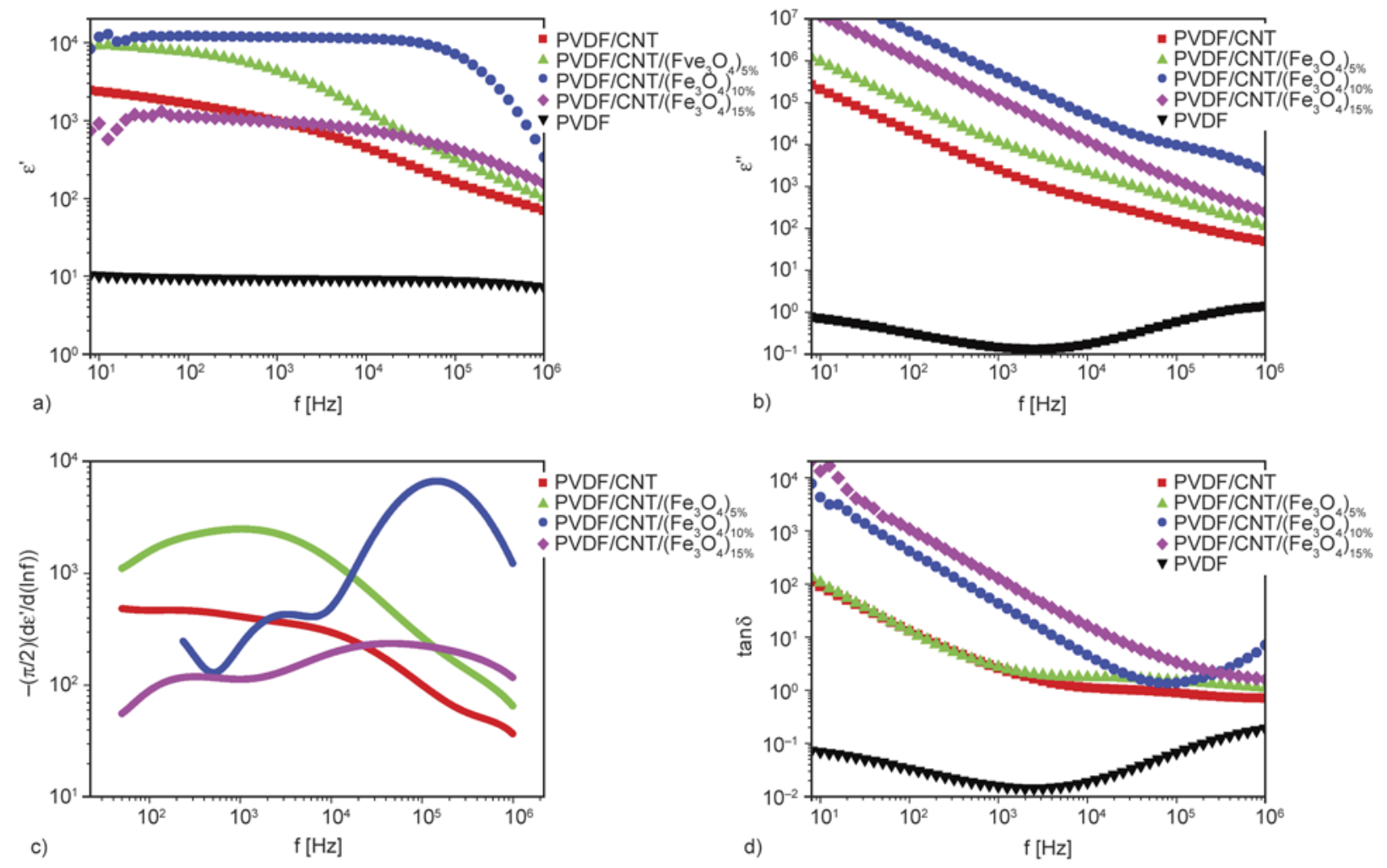

Figure 6. (a) Real part of dielectric permittivity, (b) imaginary part of dielectric permittivity, (c) imaginary part of dielectric permittivity after subtraction of DC conductivity according to the Equation (3) and (d) dissipation factor $\tan \delta$ as a function of frequency for PVDF system at room temperature 
tivity values at CNT content above the percolation threshold is related to the presence of a large number of nanocapacitor structures together with a large dipole moment of interfacial polarization wherein the conductive CNT act as nanoelectrodes and the PVDF matrix as nanodielectrics, experiencing interfacial polarization $[42,43]$. The charges which are trapped at the nanofiller-polymer interface result in the MWS polarization effect. This leads to enormous increase in the dielectric permittivity and its strong frequency dependence at the low frequency regime.

The distribution of CNT within the insulating polymer matrix, except the formation of donor-acceptor complexes at the PVDF-CNT interface [40], forms lots of nanocapacitors connected not only in series but also in parallel combinations, while this nanocapacitor's formation can significantly improve the dielectric permittivity of the nanocomposites [44, 45]. Of course, the presence of the magnetite inclusions is expected to affect this nanocapacitors formation. As shown in Figure $6 \mathrm{a}$, at the highest $\mathrm{Fe}_{3} \mathrm{O}_{4}$ content (15 wt\%) the value of $\varepsilon^{\prime}(1121)$ is lower than that of PVDF/CNT (1636) at $100 \mathrm{kHz}$. This fact indicates a significant differentiation in the formation of nanocapacitors at higher $\mathrm{Fe}_{3} \mathrm{O}_{4}$ content. More specifically, at high $\mathrm{Fe}_{3} \mathrm{O}_{4}$ content it is possible that the $\mathrm{Fe}_{3} \mathrm{O}_{4}$ nanoparticles increase the insulatinge gaps between CNT which led to a reduction in the dielectric permittivity of nanocapacitors. The capacitance has an inverse relationship with the thickness of dielectric materials and therefore an increase in nanodielectric thickness leads to a reduction in capacitance despite the polar nature of $\mathrm{Fe}_{3} \mathrm{O}_{4}$.

In the PVDF-based nanocomposites, overall three relaxations are observed in the dielectric relaxation frequency spectra. From the low - frequencies to the high - frequencies, these relaxations were identified as MWS interfacial polarization, $\alpha_{\mathrm{c}}$ relaxation and $\alpha_{\alpha}$ relaxation, respectively. Here, two dielectric relaxations are evident in pristine PVDF at room temperature in the frequency spectra as shown in Figure $6 \mathrm{~b}$. The first peak at frequency higher than $1 \mathrm{MHz}$ is the $\alpha_{\alpha}$ relaxation, also referred to as the primary relaxation. The frequency limit of the instrument constrained the full view of this relaxation. However, earlier works have confirmed the peak around $1 \mathrm{MHz}$ is related to the micro-Brownian cooperative motions of the main chain backbone and is essentially the dielectric manifestation of the glass transition temperature of the PVDF [46-48]. The second relaxation peak observed at lower than $10 \mathrm{~Hz}$ is the $\alpha_{c}$ relaxation and is attributed to molecular motions (rotation and twisting with a small lengthwise translation of the crystalline chain) of the PVDF crystalline region [47]. All the previous relaxations should be affected by the presence of the conductive CNT and semi-conductive $\mathrm{Fe}_{3} \mathrm{O}_{4}$ fillers. It was found that crystalline relaxation is not affected by the addition of the $\mathrm{Fe}_{3} \mathrm{O}_{4}$ filler in $\mathrm{PVDF} /$ $\mathrm{Fe}_{3} \mathrm{O}_{4}$ systems, while $\mathrm{Fe}_{3} \mathrm{O}_{4}$ loading has shown retardation in the glass transition dynamics [48].

As seen in Figure 6b, the presence of CNT makes almost the overall frequency spectra to be dominated by the effects related to the DC conductivity, which result in high values of $\varepsilon^{\prime \prime}$. The dielectric losses follow an $\omega^{-1}$ dependence according to $\varepsilon^{\prime \prime}=$ $\sigma_{\mathrm{dc}} /\left(\varepsilon_{0} \cdot \omega\right)$, where $\varepsilon_{0}$ is permittivity of vacuum and $\omega=2 \pi f$ the angular frequency. In the linear segment of $\log \varepsilon^{\prime \prime} v s . \log f$ representation of Figure $6 \mathrm{~b}$ the sample $\mathrm{PVDF} / \mathrm{CNT} /\left(\mathrm{Fe}_{3} \mathrm{O}_{4}\right)_{10 \%}$ presents higher losses, while the one of PVDF/CNT the lower. Deviation from the linear dependence $\omega^{-1}$ of the losses $\varepsilon^{\prime \prime}$ is present at higher frequencies in all nanocomposites. Especially, one shoulder is evidence above $100 \mathrm{kHz}$ for the PVDF/CNT/ $\left(\mathrm{Fe}_{3} \mathrm{O}_{4}\right)_{10 \%}$, and its high values of $\varepsilon^{\prime \prime}$ suggest that it should be related to the motion of charges. The dominant contribution of Ohmic conduction makes difficult to extract information about the characteristics of dielectric relaxations which take place in nanocomposites as a result of nanofillers. One convenient technique to eliminate the contribution of Ohmic conduction is based on the following derivation (Equation (3)) [49]:

$\varepsilon_{\text {deriv }}^{\prime \prime}=-\frac{\pi}{2} \cdot \frac{\partial \varepsilon^{\prime}(f)}{\partial \ln f} \approx \varepsilon^{\prime \prime}$

which yields approximately the dielectric loss for the case of broad peaks. As a result, one can obtain conductivity-free dielectric loss peaks as depicted in the Figure 6c. The losses in PVDF/CNT occupy the whole frequency window with a tendency for saturation at lowest frequencies and a peak could be read at $170 \mathrm{~Hz}$. The sample with the lowest $\mathrm{Fe}_{3} \mathrm{O}_{4}$ content also shows a broad peak with maximum value of dielectric loss, $\varepsilon^{\prime \prime}{ }_{\max }$, at frequency $1 \mathrm{kHz}$. The samples with the highest $\mathrm{Fe}_{3} \mathrm{O}_{4}$ concentrations (10 and $15 \mathrm{wt} \%$ ) show two distinct peaks where the one at high frequency is more dominant. The high frequency peaks are located at frequencies $145 \mathrm{kHz}$ 
and $46 \mathrm{kHz}$ for the specimens $\mathrm{PVDF} / \mathrm{CNT} /\left(\mathrm{Fe}_{3} \mathrm{O}_{4}\right)_{10 \%}$ and $\mathrm{PVDF} / \mathrm{CNT} /\left(\mathrm{Fe}_{3} \mathrm{O}_{4}\right)_{15 \%}$ respectively. For the same specimens the low frequency peaks occur at frequencies 3.3 and $330 \mathrm{kHz}$, respectively.

The high values of dielectric losses, $\varepsilon^{\prime \prime}{ }_{\max }$, of the Figure $6 \mathrm{c}$ peaks clearly suggest that the these relaxations, should be related to short range electric charges motion. Also, the values of the dielectric permittivity of the components (PVDF, CNT and $\mathrm{Fe}_{3} \mathrm{O}_{4}$ ), cannot explain the high permittivity values of nanocomposites in terms of simple mixing if one does not take place interfacial polarization effects. Thus, the loss peak which was detected at $170 \mathrm{~Hz}$ in PVDF/ CNT (Figure 6c), should be related to the MWS interfacial polarization due to the formation of donoracceptor complexes at the PVDF-CNT interface in conjunction with the nanocapacitor structure of $\mathrm{CNT}$ and PVDF matrix. At the lower $\mathrm{Fe}_{3} \mathrm{O}_{4}$ content ( $5 \mathrm{wt} \%$ ), the presence of a broad loss peak at $1 \mathrm{kHz}$ in Figure 6c, suggests that the formation of donoracceptor complexes at the PVDF-CNT interface in conjunction with the nanocapacitor structure of CNT and PVDF matrix, has also the dominant role in the appearance of MWS interfacial polarization mechanism.

On the other hand, at higher $\mathrm{Fe}_{3} \mathrm{O}_{4}$ content (10 and $15 \mathrm{wt} \%$ ) the low frequency loss peaks present a remarkable reduction of dielectric losses $\left(\varepsilon^{\prime \prime}{ }_{\max }\right)$ values, which indicate that the presence of $\mathrm{Fe}_{3} \mathrm{O}_{4}$ inclusions restrict the contribution of nanocapacitor structure of CNT-PVDF matrix to the formation of interfacial polarization effects. This behaviour is consistent with the insulating effect of $\mathrm{Fe}_{3} \mathrm{O}_{4}$ inclusions discussed previously, commenting on the results of Figure 6a. The presence of semi-conductive $\mathrm{Fe}_{3} \mathrm{O}_{4}$, is expected to enhance the complexity as well as the number of interfaces between the components of our ternary system. The appearance of a second loss peak, more enhanced, at higher frequencies in PVDF/CNT/ $\left(\mathrm{Fe}_{3} \mathrm{O}_{4}\right)_{10 \%}$ and PVDF/CNT/ $\left(\mathrm{Fe}_{3} \mathrm{O}_{4}\right)_{15 \%}$ nanocomposites, should be connected to the $\mathrm{Fe}_{3} \mathrm{O}_{4}$ inclusions effects. These higher frequency relaxations, play a major role in forming the dielectric constant in PVDF/CNT/ $\left(\mathrm{Fe}_{3} \mathrm{O}_{4}\right)_{10}$ and PVDF/ $\mathrm{CNT} /\left(\mathrm{Fe}_{3} \mathrm{O}_{4}\right)_{15 \%}$ nanocomposites. In a study of $\mathrm{Fe}_{3} \mathrm{O}_{4}$-polypyrrole hybrid nanocomposites carried out by Dey et al. [41], the interface between polypyrrole and $\mathrm{Fe}_{3} \mathrm{O}_{4}$, was found to play an important role in producing a large dielectric constant. A MWS type interfacial polarization mechanism appears at high frequency range, caused from $\mathrm{Fe}_{3} \mathrm{O}_{4}$-polypyrrole interfaces and leads to a high dielectric constant in the nanocomposite. So, it is possible the second loss peak at higher frequencies in PVDF/CNT/ $\left(\mathrm{Fe}_{3} \mathrm{O}_{4}\right)_{10 \%}$ and $\mathrm{PVDF} / \mathrm{CNT} /\left(\mathrm{Fe}_{3} \mathrm{O}_{4}\right)_{15} \%$ nanocomposites, to be related with a MWS type interfacial polarization caused by a synergetic effect that occurs between the PVDF-CNT matrix and $\mathrm{Fe}_{3} \mathrm{O}_{4}$ inclusions interfaces.

The real and imaginary parts, $\varepsilon^{\prime}$ and $\varepsilon^{\prime \prime}$, of the complex dielectric function $\varepsilon^{*}=\varepsilon^{\prime}-j \varepsilon^{\prime \prime}$, define the dissipation factor $\tan \delta=\varepsilon^{\prime \prime} / \varepsilon^{\prime}$ which is of great importance in technological applications since it reflects the ratio of dissipated energy per stored energy. Figure $6 \mathrm{~d}$ shows the dissipation factors of PVDF and its nanocomposites. It can be observed that the dissipation factor of nanocomposites present enhanced values in relation to the pure PVDF and as the frequency decreases, $\tan \delta$ almost linearly increases several orders of magnitude. While in the pure PVDF $\tan \delta$ takes values lower than 0.1 at all frequency spectra, the nanocomposites exhibit values higher than 1 almost at all frequency range. The nanocomposite $\mathrm{PVDF} / \mathrm{CNT} /\left(\mathrm{Fe}_{3} \mathrm{O}_{4}\right)_{15} \%$ with the higher dissipation factor, at lower frequency range, takes value of 127 at $1 \mathrm{kHz}$. Both PVDF/CNT/( $\left.\mathrm{Fe}_{3} \mathrm{O}_{4}\right)_{5 \%}$ and PVDF/ CNT exhibit almost the same frequency dependence of dissipation factor at lower frequency region and also present the lower value of 2.7 at $1 \mathrm{kHz}$.

As one can observe in Figure 6d, one shoulder appears above $10 \mathrm{kHz}$ in both $\mathrm{PVDF} / \mathrm{CNT}$ and $\mathrm{PVDF} /$ $\mathrm{CNT} /\left(\mathrm{Fe}_{3} \mathrm{O}_{4}\right)_{5 \%}$. For the same relaxation process the peak in $\tan \delta$ is shifted at higher frequencies relatively to the one of imaginary part of dielectric permittivity. The relaxation ratio, $\Delta \varepsilon / \varepsilon_{\infty}+1$, as well as the distribution parameters of the process will determine how close or far apart the peaks will be [50]. Therefore, the shoulders in $\tan \delta$ should be related to the relaxation process detected at low frequencies in both nanocomposites (Figure 6c).

The alternating current (AC) conductivity is a proper representation to correlate the macroscopic measurement to the microscopic movement of the charge carriers. Figure 7a shows the AC electrical conductivity of the studied system, which is determined by using the dielectric data as $\sigma^{\prime}=\varepsilon_{0} \varepsilon^{\prime \prime} \omega$. All nanocomposites exhibit a plateau at lower frequencies which corresponds to DC conductivity, $\sigma_{\mathrm{dc}}$. DC conductivity measurements which carried out with Keithley 2440 Sourcemeter confirm the previous allegation 
with high accuracy. The lower value of DC conductivity between the nanocomposites is exhibited by $\mathrm{PVDF} / \mathrm{CNT}$. At $10 \mathrm{~Hz}, \mathrm{PVDF} / \mathrm{CNT}$ presents a value higher more than 5 orders of magnitude relatively to that of pure PVDF. This is an expected behavior since CNT content is well above the value of percolation threshold. By increasing the $\mathrm{Fe}_{3} \mathrm{O}_{4}$ content, DC conductivity increases up to $\mathrm{PVDF} / \mathrm{CNT} /$ $\left(\mathrm{Fe}_{3} \mathrm{O}_{4}\right)_{10 \%}$ which presents the maximum value of $2.8 \cdot 10^{-4} \mathrm{~S} / \mathrm{cm}$, more than two orders of magnitude higher than this of PVDF/CNT. At the higher $\mathrm{Fe}_{3} \mathrm{O}_{4}$ content, the DC conductivity reduces at a value of $6.7 \cdot 10^{-5} \mathrm{~S} / \mathrm{cm}$ which is significantly higher than these of the rest two nanocomposites PVDF/CNT and $\mathrm{PVDF} / \mathrm{CNT} /\left(\mathrm{Fe}_{3} \mathrm{O}_{4}\right)_{5 \%}$. The reduced value of DC conductivity at high $\mathrm{Fe}_{3} \mathrm{O}_{4}$ content should be related to the barrier effect of the $\mathrm{Fe}_{3} \mathrm{O}_{4}$ nanoparticles that disrupted the conductive network of CNT and made it more difficult for charge carriers to move throughout the network [51].

Electric modulus formalism has been proved very efficient in analyzing dielectric data of polymer matrix nanocomposites. The electric modulus is defined by Equation (4) as the inverse quantity of complex dielectric permittivity [52]:

$M^{*}=M^{\prime}+j M^{\prime \prime}=\frac{1}{\varepsilon^{*}}=\frac{\varepsilon^{\prime}}{\varepsilon^{\prime 2}+\varepsilon^{\prime 2}}+j \frac{\varepsilon^{\prime \prime}}{\varepsilon^{\prime 2}+\varepsilon^{\prime 2}}$

where $\varepsilon^{\prime}, M^{\prime}$ are the real and $\varepsilon^{\prime \prime}, M^{\prime \prime}$ the imaginary parts of dielectric permittivity and electric modulus, respectively. Figure $7 \mathrm{~b}$ shows the dependence of $M^{\prime \prime}$ as a function of frequency $f$, at room temperature. In pure PVDF, the peak which appears below $10 \mathrm{~Hz}$ is assigned as the $\alpha_{c}$ relaxation, while the one appearing at frequency higher than $1 \mathrm{MHz}$ is the $\alpha_{\alpha}$ relaxation. In nanocomposites the contribution of a high frequency relaxation is dominant, while a shoulder exists at lower frequency range which is more distinct in PVDF/CNT/ $\left(\mathrm{Fe}_{3} \mathrm{O}_{4}\right)_{10 \%}$. Figure 7c shows the best fitting of the following relation which consists of a sum of a Havriliak-Negami expression (Equation (5)) and a linear term:

$M^{\prime \prime}=\operatorname{Im}\left\{\frac{\Delta M^{\prime}}{\left(1+\left(j \omega \tau_{\mathrm{HN}}\right)^{\alpha}\right)^{\beta}}\right\}+A \omega^{\mathrm{n}}$

to the experimental data of $\mathrm{PVDF} / \mathrm{CNT} /\left(\mathrm{Fe}_{3} \mathrm{O}_{4}\right)_{10 \%}$ in order to separate these two contributions. The first term of Equation (4) represents the contribution of the lower frequencies relaxation, where $\Delta M^{\prime}=$ $M_{\infty}^{\prime}-M_{\mathrm{s}}^{\prime}, M_{\infty}^{\prime}=1 / \varepsilon_{\infty}^{\prime}, M_{\mathrm{s}}^{\prime}=1 / \varepsilon_{\mathrm{s}}^{\prime} . \tau_{\mathrm{HN}}$ is a characteris-
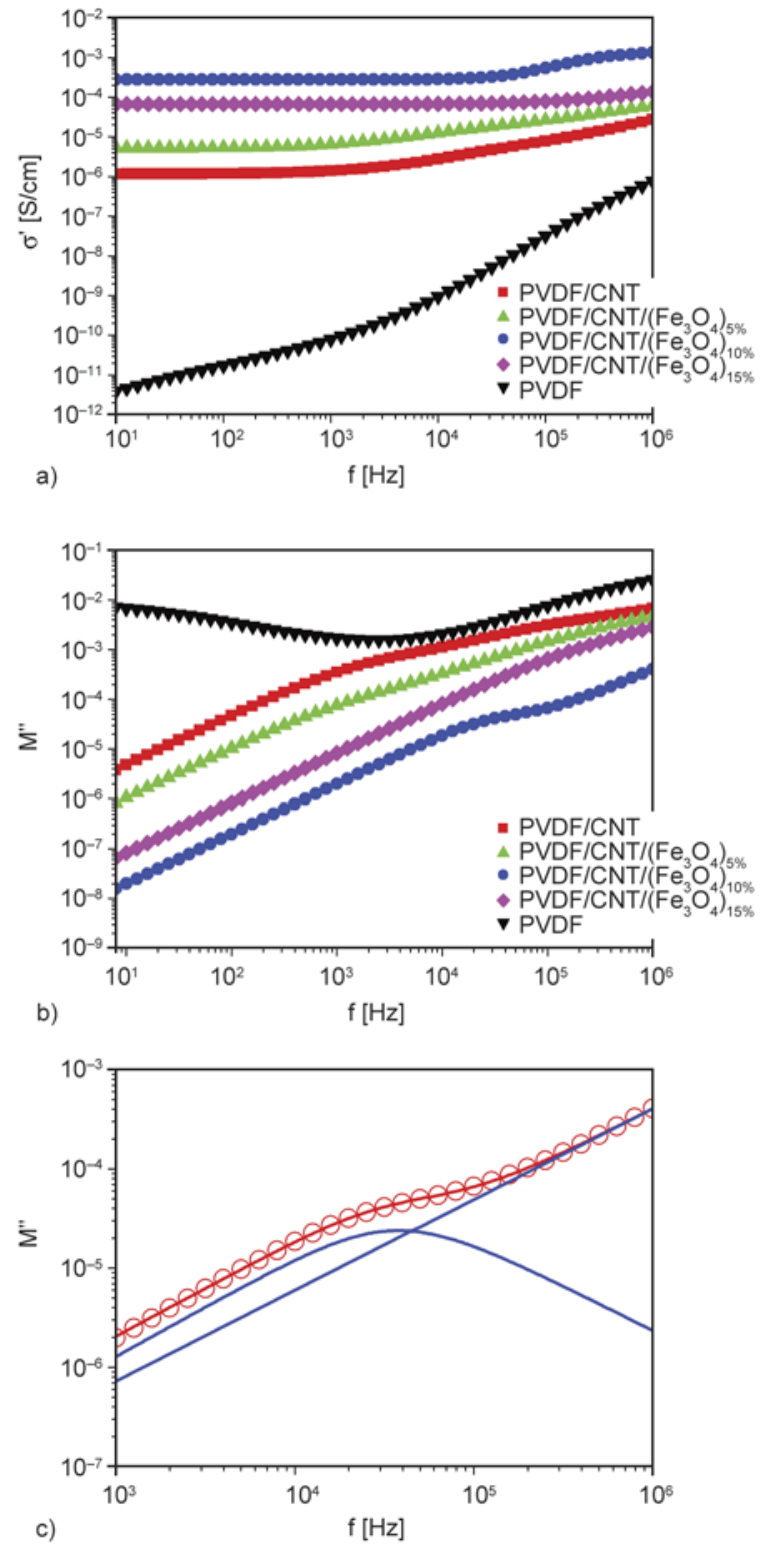

Figure 7. (a) AC electrical conductivity as a function of frequency for PVDF system at room temperature, (b) dependence of imaginary part of electric modulus as a function of frequency, for PVDF system at room temperature, (c) experimental data (red circles), total (red line) and individual (blue lines) fitting curves of the imaginary part $M^{\prime \prime}$ of electric modulus according to Equation (4) for the sample with $10 \mathrm{wt} \% \mathrm{Fe}_{3} \mathrm{O}_{4}$ with parameters values: $\alpha=1$, $\beta=0.91,1 /\left(2 \pi \tau_{\mathrm{HN}}\right)=35.3 \mathrm{kHz}, \Delta M^{\prime}=5 \cdot 10^{-5}$, $A=1.32 \cdot 10^{-9}$ and $n=0.91$.

tic relaxation time. $\alpha$ and $\beta$ are the Havriliak-Negami shape parameters which correspond to the widening and asymmetry of relaxation times distribution and $\omega=2 \pi f$ the angular frequency of the applied electric field. The second term of Equation (4) represents the linear contribution of the higher frequency relaxation to the $\log -\log$ frequency spectrum. The 
parameter A reflects the position and the strength of this mechanism while $n$ defines the slope of the linear left-side contribution.

$\mathrm{DC}$ conductivity is given through the relation $\sigma_{\mathrm{dc}}=$ $\varepsilon_{0} \varepsilon_{\mathrm{s}} \omega_{0}$, where $\varepsilon_{0}$ is the permittivity of vacuum, $\varepsilon_{\mathrm{s}}$ the dielectric constant and as $\omega_{0}$ is taken the angular frequency which corresponds to maximum peak position of conductivity relaxation mechanism in the imaginary part of electric modules function, $\omega_{0}=$ $2 \pi f_{\max , \mathrm{M}^{\prime \prime}}[53]$. As shown in Figure $7 \mathrm{c}$ the relaxation presents a maximum value of $M^{\prime \prime}$ at frequency $f_{\max , \mathrm{M}^{\prime \prime}}=36.6 \mathrm{kHz}$.

If we choose the value of $\varepsilon^{\prime}=12140$ at $100 \mathrm{~Hz}$ as the value of dielectric constant of PVDF/CNT/ $\left(\mathrm{Fe}_{3} \mathrm{O}_{4}\right)_{10 \%}$, then according to the previous relation the DC conductivity is found to be $2.5 \cdot 10^{-4} \mathrm{~S} / \mathrm{cm}$. This value is very close to the corresponding one extracted from the plateau of Figure $7 \mathrm{a}$, which is $2.8 \cdot 10^{-4} \mathrm{~S} / \mathrm{cm}$. This fact is a strong indication that the relaxation which appears as shoulder in $\log M^{\prime \prime}-\log f$ plots of Figure $7 \mathrm{~b}$ is the conductivity mechanism and $f_{\text {max }, \mathrm{M}^{\prime \prime}}$ value separates the regions of shortrange and long-range mobility of charges at the right-hand and left-hand sides of $M^{\prime \prime}$ maximum, respectively [54].

As it is obvious in Figure 7c, the shoulder of PVDF/ $\mathrm{CNT} /\left(\mathrm{Fe}_{3} \mathrm{O}_{4}\right)_{10 \%}$ exists at the higher frequency, while the shoulder of PVDF/CNT is present at lower frequency. The characteristic frequency $\omega_{0}$ is closely related to the relaxation time of conductivity mechanism via the relation $\tau_{0}=1 / \omega_{0}$. So, higher $\omega_{0}$ means faster conductivity relaxation. According to the relation $\sigma_{\mathrm{dc}}=\varepsilon_{0} \varepsilon_{\mathrm{s}} \omega_{0}$, the DC conductivity is proportional to both, dielectric permittivity and characteristic frequency $\omega_{0}$. PVDF/CNT/ $\left(\mathrm{Fe}_{3} \mathrm{O}_{4}\right)_{10 \%}$ characterized from the higher values of dielectric permittivity and $\omega_{0}$, so it is expected to have the higher $\sigma_{\mathrm{dc}}$ value. On the other hand, $\mathrm{PVDF} / \mathrm{CNT} /\left(\mathrm{Fe}_{3} \mathrm{O}_{4}\right)_{15 \%}$ although presents the lower $\varepsilon^{\prime}$ value, the significantly high value of $\omega_{0}$ dominates and so its $\sigma_{\mathrm{dc}}$ value is higher than that of PVDF/CNT and PVDF/CNT/ $\left(\mathrm{Fe}_{3} \mathrm{O}_{4}\right)_{5 \%}$.

The present study, which is related to the morphological, thermal, magnetic, dielectric and electrical characterization of the novel $\mathrm{PVDF} / \mathrm{CNT} / \mathrm{Fe}_{3} \mathrm{O}_{4}$ ternary system, was carried out at room temperature. Investigation of the dielectric properties as well as electrical properties at different temperature profiles using the same nanocomposites will be performed in an ensuing study.

\section{Conclusions}

Nanocomposites consisting of PVDF as matrix, acting as ferroelectric and piezoelectric phase, $\mathrm{Fe}_{3} \mathrm{O}_{4}$ nanopowders as magnetic (ferrite) phase and $\mathrm{CNT}$ as conductive phase were prepared by the twin screw compounding method. SEM measurements show a good dispersion of nanoinclusions in the PVDF matrix, and only at the used highest $\mathrm{Fe}_{3} \mathrm{O}_{4}$ particle concentration agglomerates containing three or more particles were observed. FTIR and XRD measurements provide clear evidence that mainly the presence of CNT induces the formation of $\beta$ phase in nanocomposites. According to DSC measurements, the degree of crystallinity is practically unaffected by the addition of CNT for the lowest concentration of $\mathrm{Fe}_{3} \mathrm{O}_{4}$ particles. For higher $\mathrm{Fe}_{3} \mathrm{O}_{4}$, content a decrease of the degree of crystallinity is observed. From magnetic measurements, apart from the ferrimagnetic behavior of the prepared nanocomposites, the gradually increase of saturation magnetization values with the magnetite content is confirmed.

The overall frequency spectrum is dominated by the effects related to DC conductivity. The removing of the effect of ohmic conductivity, revealed dielectric loss peaks. In PVDF/CNT and PVDF/CNT/ $\left(\mathrm{Fe}_{3} \mathrm{O}_{4}\right)_{5 \%}$ one broad loss peak appears at the low frequencies region. At higher $\mathrm{Fe}_{3} \mathrm{O}_{4}$ content, the influence of $\mathrm{Fe}_{3} \mathrm{O}_{4}$ nanoparticles in PVDF-CNT matrix gives rise to the existence of a second loss peak, more enhanced at higher frequencies. The high values of both, dielectric losses, $\varepsilon^{\prime \prime}{ }_{\max }$, and dielectric permittivity, $\varepsilon^{\prime}$, suggest that these loss peaks are possible related to the MWS interfacial polarization mechanisms. The first one, at lower frequencies, should be related to the formation of donor-acceptor complexes at the PVDF-CNT interface in conjunction with the nanocapacitor structure of CNT and PVDF matrix. The second one, at higher frequencies, it is possible to be caused by a synergetic effect that occurs between the PVDF-CNT matrix and $\mathrm{Fe}_{3} \mathrm{O}_{4}$ inclusions interfaces.

However, it should be noted that further investigation is needed to clarify the origin of these two peaks.

Values of dielectric permittivity were significantly enhanced in the whole frequency range due to the presence of both $\mathrm{CNT}$ and $\mathrm{Fe}_{3} \mathrm{O}_{4}$. Composites with $10 \mathrm{wt} \% \mathrm{Fe}_{3} \mathrm{O}_{4}$, present higher stability in dielectric permittivity values in almost the whole frequency 
spectrum, a behavior interesting for electronics devices applications. The incorporation of $\mathrm{Fe}_{3} \mathrm{O}_{4}$ in $\mathrm{PVDF} / \mathrm{CNT}$ matrix gradually increases the values of both, dielectric permittivity and DC conductivity, when the content of $\mathrm{Fe}_{3} \mathrm{O}_{4}$ is up to $10 \mathrm{wt} \%$. At the higher magnetite content, the role of $\mathrm{Fe}_{3} \mathrm{O}_{4}$ as insulating barrier in the PVDF/CNT matrix should be dominant. On the one hand, $\mathrm{Fe}_{3} \mathrm{O}_{4}$ nanoparticles it is possible to increase the insulating gaps between CNT which led to a reduction in the dielectric permittivity of nanocapacitors, as well as to the total dielectric permittivity. On the other hand, the possible barrier effect of $\mathrm{Fe}_{3} \mathrm{O}_{4}$ nanoparticles restricts the conductive network of $\mathrm{CNT}$ and as a result reduces the DC conductivity. $\mathrm{PVDF} / \mathrm{CNT} / \mathrm{Fe}_{3} \mathrm{O}_{4}$ ternary composites constitute a very promising system with large potential in diverse fields since combines and matches together piezoelectric, electrical, dielectric and magnetic properties.

\section{Acknowledgements}

This research has been co-financed by the European Union (European Social Fund - ESF) and Greek national funds through the Operational Program 'Education and Lifelong Learning' of the National Strategic Reference Framework (NSRF) $\square$ Research Funding Program: THALES. Investing in knowledge society through the European Social Fund. (MIS 379346).

The authors also would like to thank Associate Professor M. Angelakeris for providing access to VSM instrument.

\section{References}

[1] Sencadas V., Moreira V. M., Lanceros-Mendez S., Pouzada A. S., Filho R. G.: $\alpha$ - to $\beta$ transformation on PVDF films obtained by uniaxial stretch. Materials Science Forum, 514-516, 872-876 (2006). DOI: $10.4028 /$ www.scientific.net/MSF.514-516.872

[2] Nalwa H. S.: Ferroelectric polymers: Chemistry, physics, and applications. Marcel Dekker, New York (1995).

[3] Kepler R. G., Anderson R. A.: Piezoelectricity and pyroelectricity in polyvinylidene fluoride. Journal of Applied Physics, 49, 4490-4494 (1978).

DOI: $10.1063 / 1.325454$

[4] Lovinger A. J.: Annealing of poly(vinylidene fluoride) and formation of a fifth phase. Macromolecules, 15, 40-44 (1982).

DOI: $10.1021 / \mathrm{ma} 00229 \mathrm{a} 008$

[5] Chiang C. K., Popielarz R.: Polymer composites with high dielectric constant. Ferroelectrics, 275, 1-9 (2002). DOI: $\underline{10.1080 / 00150190214285}$
[6] Ishida H., Campbell S., Blackwell J.: General approach to nanocomposite preparation. Chemistry of Materials, 12, 1260-1267 (2000). DOI: $10.1021 / \mathrm{cm} 990479 y$

[7] Ezquerra T. A., Canalda J. C., Sanz A., Linares A.: On the electrical conductivity of PVDF composites with different carbon-based nanoadditives. Colloid and Polymer Science, 292, 1989-1998 (2014).

DOI: $10.1007 / \mathrm{s} 00396-014-3252-6$

[8] Prinz G. A.: Magnetoelectronics. Science, 282, 16601663 (1998).

DOI: $10.1126 /$ science. 282.5394 .1660

[9] Kumar J., Singh R. K., Samanta S. B., Rastogi R. C., Singh R.: Single-step magnetic patterning of iron nanoparticles in a semiconducting polymer matrix. Macromolecular Chemistry and Physics, 207, 1584-1588 (2006).

DOI: $10.1002 / \mathrm{macp} .200600260$

[10] Eerenstein W., Mathur N. D., Scott J. F.: Multiferroic and magnetoelectric materials. Nature, 442, 759-765 (2006).

DOI: 10.1038 /nature05023

[11] Yang T-I., Brown R. N. C., Kempel L. C., Kofinas P.: Magneto-dielectric properties of polymer- $\mathrm{Fe}_{3} \mathrm{O}_{4}$ nanocomposites. Journal of Magnetism and Magnetic Materials, 320, 2714-2720 (2008).

DOI: $10.1016 /$ j.jmmm.2008.06.008

[12] Wang X., Li W., Luo L., Fang Z., Zhang J., Zhu Y.: High dielectric constant and superparamagnetic polymer-based nanocomposites induced by percolation effect. Journal of Applied Polymer Science, 125, 27112715 (2012). DOI: 10.1002/app.36587

[13] Prabhakaran T., Hemalatha J.: Ferroelectric and magnetic studies on unpoled poly (vinylidine fluoride)/ $\mathrm{Fe}_{3} \mathrm{O}_{4}$ magnetoelectric nanocomposite structures. Materials Chemistry and Physics, 137, 781-787 (2013). DOI: 10.1016/j.matchemphys.2012.09.064

[14] Bhatt A. S., Krishna Bhat D., Santosh M. S.: Crystallinity, conductivity, and magnetic properties of PVDF- $\mathrm{Fe}_{3} \mathrm{O}_{4}$ composite films. Journal of Applied Polymer Science, 119, 968-972 (2011).

DOI: $10.1002 / \mathrm{app} .32796$

[15] Xu C., Ouyang C., Jia R., Li Y., Wang X..: Magnetic and optical properties of poly(vinylidene difluoride)/ $\mathrm{Fe}_{3} \mathrm{O}_{4}$ nanocomposite prepared by coprecipitation approach. Journal of Applied Polymer Science, 111, 1763-1768 (2009).

DOI: $10.1002 / a p p .29194$

[16] Zhang W-B., Zhang Z-X., Yang J-H., Huang T., Zhang N., Zheng X-T., Wang Y., Zhou Z-W.: Largely enhanced thermal conductivity of poly(vinylidene fluoride)/carbon nanotube composites achieved by adding graphene oxide. Carbon, 90, 242-254 (2015). DOI: $10.1016 /$ j.carbon.2015.04.040 
[17] Liu Z. D., Feng Y., Li W. L.: High dielectric constant and low loss of polymeric dielectric composites filled by carbon nanotubes adhering $\mathrm{BaTiO}_{3}$ hybrid particles. RSC Advances, 5, 29017-29021 (2015).

DOI: $10.1039 / C 5 R A 00639 B$

[18] Bauhofer W., Kovacs J. Z.: A review and analysis of electrical percolation in carbon nanotube polymer composites. Composites Science and Technology, 69, 14861498 (2009).

DOI: 10.1016/j.compscitech.2008.06.018

[19] Li Q., Xue Q. Z., Gao X. L., Zheng Q. B.: Temperature dependence of the electrical properties of the carbon nanotube/polymer composites. Express Polymer Letters, 3, 769-777 (2009).

DOI: 10.3144/expresspolymlett.2009.95

[20] Mandal B. P., Vasundhara K., Abdelhamid E., Lawes G., Salunke H. G., Tyagi A. K.: Improvement of magnetodielectric coupling by surface functionalization of nickel nanoparticles in ni and polyvinylidene fluoride nanohybrids. The Journal of Physical Chemistry C, 118, 20819-20825 (2014). DOI: 10.1021/jp5065787

[21] Lanceros-Mendez S., Mano J. F., Costa A. M., Schmidt V. H.: FTIR and DSC studies of mechanically deformed $\beta$-PVDF films. Journal of Macromolecular Science Part B: Physics, 40, 517-527 (2001).

DOI: $10.1081 / \mathrm{MB}-100106174$

[22] Vasundhara K., Mandal B. P., Tyagi A. K.: Enhancement of dielectric permittivity and ferroelectricity of a modified cobalt nanoparticle and polyvinylidene fluoride based composite. RSC Advances, 5, 8591-8597 (2015). DOI: 10.1039/C4RA09292A

[23] Salimi A., Yousefi A. A.: Analysis method: FTIR studies of $\beta$-phase crystal formation in stretched PVDF films. Polymer Testing, 22, 699- 704 (2003).

DOI: 10.1016/S0142-9418(03)00003-5

[24] Gregorio Jr. R., Cestari M.: Effect of crystallization temperature on the crystalline phase content and morphology of poly(vinylidene fluoride). Journal of Polymer Science Part B: Polymer Physics, 32, 859-870 (1994).

DOI: 10.1002/polb.1994.090320509

[25] Matsushige K., Nagata K., Imada S., Takemura T.: The II-I crystal transformation of poly(vinylidene fluoride) under tensile and compressional stresses. Polymer, 21, 1391-1397 (1980).

DOI: 10.1016/0032-3861(80)90138-X

[26] Ke K., Pötschke P., Jehnichen D., Fischer D., Voit B.: Achieving $\beta$-phase poly(vinylidene fluoride) from melt cooling: Effect of surface functionalized carbon nanotubes. Polymer, 55, 611-619 (2014).

DOI: $10.1016 /$ j.polymer.2013.12.014
[27] Georgousis G., Pandis C., Kalamiotis A., Georgiopoulos P., Kyritsis A., Kontou E., Pissis P., Micusik M., Czanikova K., Kulicek J., Omastova M.: Strain sensing in polymer/carbon nanotube composites by electrical resistance measurement. Composites Part B: Engineering, 68, 162-169 (2015).

DOI: 10.1016/j.compositesb.2014.08.027

[28] Martins P., Costa C., Lanceros-Mendez S.: Nucleation of electroactive $\beta$-phase poly(vinilidene fluoride) with $\mathrm{CoFe}_{2} \mathrm{O}_{4}$ and $\mathrm{NiFe}_{2} \mathrm{O}_{4}$ nanofillers: A new method for the preparation of multiferroic nanocomposites. Applied Physics A, 103, 233-237 (2011).

DOI: $10.1007 / \mathrm{s} 00339-010-6003-7$

[29] Martins P., Costa C. M., Botelho G., Lanceros-Mendez S., Barandiaran J. M., Gutierrez J.: Dielectric and magnetic properties of ferrite/poly(vinylidene fluoride) nanocomposites. Materials Chemistry and Physics, 131, 698-705 (2012).

DOI: 10.1016/j.matchemphys.2011.10.037

[30] Martins P., Lopes A. C., Lanceros-Mendez S.: Electroactive phases of poly(vinylidene fluoride): Determination, processing and applications. Progress in Polymer Science, 39, 683-706 (2014).

DOI: $10.1016 /$ j.progpolymsci.2013.07.006

[31] Levi N., Czerw R., Xing S., Iyer P., Carroll D. L.: Properties of polyvinylidene difluoride-carbon nanotube blends. Nano Letters, 4, 1267-1271 (2004). DOI: $10.1021 / \mathrm{n} 10494203$

[32] Huang X., Jiang P., Kim C., Liu F., Yin Y.: Influence of aspect ratio of carbon nanotubes on crystalline phases and dielectric properties of poly(vinylidene fluoride). European Polymer Journal, 45, 377-386 (2009). DOI: $10.1016 / j$.eurpolymj.2008.11.018

[33] Campbell D., White J. R.: Polymer characterization: Physical techniques. Chapman and Hall, London (1989).

[34] Assouline E., Lustiger A., Barber A. H., Cooper C. A., Klein E., Wachtel E., Wagner H. D.: Nucleation ability of multiwall carbon nanotubes in polypropylene composites. Journal of Polymer Science, Part B: Polymer Physics, 41, 520-527 (2003).

DOI: $10.1002 /$ polb.10394

[35] Mičušík M., Omastová M., Pionteck J., Pandis C., Logakis E., Pissis P.: Influence of surface treatment of multiwall carbon nanotubes on the properties of polypropylene/carbon nanotubes nanocomposites. Polymers for Advanced Technologies, 22, 38-47 (2011). DOI: $10.1002 /$ pat. 1745

[36] Bhattacharyya A. R., Sreekumar T. V., Liu T., Kumar S., Ericson L. M., Hauge R. H., Smalley R. E.: Crystallization and orientation studies in polypropylene/ single wall carbon nanotube composite. Polymer, 44, 2373-2377 (2003).

DOI: $10.1016 / \mathrm{S} 0032-3861(03) 00073-9$ 
[37] Nakagawa K., Ishida Y.: Annealing effects in poly (vinylidene fluoride) as revealed by specific volume measurements, differential scanning calorimetry, and electron microscopy. Journal of Polymer Science: Polymer Physics Edition, 11, 2153-2171 (1973).

DOI: $10.1002 /$ pol.1973.180111107

[38] Gregorio Jr R.: Determination of the $\alpha, \beta$, and $\gamma$ crystalline phases of poly(vinylidene fluoride) films prepared at different conditions. Journal of Applied Polymer Science, 100, 3272-3279 (2006).

DOI: $10.1002 / a p p .23137$

[39] Cullity B. D., Graham C. D.: Introduction to magnetic materials. Wiley, New Jersey (2009).

[40] Yuan J-K., Yao S-H., Dang Z-M., Sylvestre A., Genestoux M., Bai J.: Giant dielectric permittivity nanocomposites: Realizing true potential of pristine carbon nanotubes in polyvinylidene fluoride matrix through an enhanced interfacial interaction. Journal of Physical Chemistry C, 115, 5515-5521 (2011).

DOI: $10.1021 / j p 1117163$

[41] Dey A., De A., De S. K.: Electrical transport and dielectric relaxation in $\mathrm{Fe}_{3} \mathrm{O}_{4}$-polypyrrole hybrid nanocomposites. Journal of Physics: Condensed Matter, 17, 5895-5910 (2005).

DOI: $10.1088 / 0953-8984 / 17 / 37 / 025$

[42] Wang L., Dang Z-M.: Carbon nanotube composites with high dielectric constant at low percolation threshold. Applied Physics Letters, 87, 042903/1-042903/3 (2005).

DOI: $10.1063 / 1.1996842$

[43] Arjmand M., Apperley T., Okoniewski M., Sundararaj U.: Comparative study of electromagnetic interference shielding properties of injection molded versus compression molded multi-walled carbon nanotube/polystyrene composites. Carbon, 50, 5126-5134 (2012). DOI: $10.1016 /$ j.carbon.2012.06.053

[44] Simoes R., Silva J., Vaia R., Sencadas V., Costa P., Gomes J., Lanceros-Méndez S.: Low percolation transitions in carbon nanotube networks dispersed in a polymer matrix: Dielectric properties, simulations and experiments. Nanotechnology, 20, 035703/1-035703/8 (2009).

DOI: $10.1088 / 0957-4484 / 20 / 3 / 035703$

[45] Yao S-H., Dang Z-M., Xu H-P., Jiang M-J., Bai J.: Exploration of dielectric constant dependence on evolution of microstructure in nanotube/ferroelectric polymer nanocomposites. Applied Physics Letters, 92, 082902/1-082902/3 (2008).

DOI: $10.1063 / 1.2870104$
[46] Bello A., Laredo E., Grimau M.: Distribution of relaxation times from dielectric spectroscopy using Monte Carlo simulated annealing: Application to $\alpha-P V D F$. Physical Review: B, 60, 12764-12774 (1999).

DOI: 10.1103/PhysRevB.60.12764

[47] Kochervinskii V. V., Malyshkina I. A., Markin G. V., Gavrilova N. D., Bessonova N. P.: Dielectric relaxation in vinylidene fluoride-hexafluoropropylene copolymers. Journal of Applied Polymer Science, 105, 1107-1117 (2007). DOI: $10.1002 / \mathrm{app} .26145$

[48] Chanmal C., Jog J.: Dielectric relaxation spectroscopy for polymer nanocomposites. in 'Characterization techniques for polymer nanocomposites' (ed.: Mittal V.) Wiley, New York, 167-184 (2012). DOI: $10.1002 / 9783527654505 . c h 7$

[49] Wübbenhorst M., Turnhout J.: Conduction - free dielectric $\operatorname{loss} \delta \varepsilon / \delta \ln f-$ A powerful tool for the analysis of strong (ion) conducting dielectric materials. Dielectrics Newsletter: Scientific Newsletters for Dielectric and Impedance Spectroscopy, 14, 1-3 (2000).

[50] Cao W., Gerhardt R.: Calculation of various relaxation times and conductivity for a single dielectric relaxation process. Solid State Ionics, 42, 213-221 (1990). DOI: 10.1016/0167-2738(90)90010-O

[51] Sadeghi F., Ajji A.: Study of crystal structure of (polyvinylidene fluoride/clay) nanocomposite films: Effect of process conditions and clay type. Polymer Engineering and Science, 49, 200-207 (2009).

DOI: $10.1002 /$ pen.21248

[52] Macedo P. B., Moynihan C. T., Bose R.: The role of ionic diffusion in polarization in vitreous ionic conductors. Physics and Chemistry Glasses, 13, 171-179 (1972).

[53] Macdonald J. R.: Comments on the electric modulus formalism model and superior alternatives to it for the analysis of the frequency response of ionic conductors. Journal of Physics and Chemistry of Solids, 70, 546554 (2009).

DOI: $10.1016 /$ j.jpcs.2008.12.012

[54] Nikonorova N. A., Barmatov E. B., Pebalk D. A., Barmatova M. V., Dominguez-Espinosa G., Diaz-Calleja R., Pissis P.: Electrical properties of nanocomposites based on comb-shaped nematic polymer and silver nanoparticles. Journal of Physical Chemistry C, 111, 8451-8458 (2007).

DOI: $10.1021 / \mathrm{jp} 068688 \mathrm{a}$ 